\title{
Proheksadioni-kalsiumin vaikutus mansikan kasvuun ja hankasilmujen erilaistumiseen
}

Timo Hytönen ja Olavi Junttila

Soveltavan biologian laitos, PL 27,00014 Helsingin yliopisto,timo.hytonen@helsinki.fi

\section{Johdanto}

Lyhyt- ja pitkäversojen muodostus on tyypillistä puutarhamansikalla (Fragaria $\mathrm{x}$ ananassa Duch.), kuten monilla muilla Rosaceae-heimon kasveilla (Guttridge 1985). Mansikan juurakko on lyhytverso, jonka jokaisessa nivelessä on yksi lehti ja yksi hankasilmu. Hankasilmut voivat erilaistua lyhytversoiksi eli juurakon haaroiksi tai pitkäversoiksi eli rönsyiksi, joissa on kaksi pitkää nivelväliä ennen rönsytainta. Mansikan kukinto muodostuu juurakon kärkikasvupisteestä, jolloin ylin hankasilmu jatkaa juurakon vegetatiivista kasvua.

Suurin osa Suomessa viljeltävistä mansikkalajikkeista on lyhyenpäivänlajikkeita, joiden kukintainduktiota säätelee ensisijaisesti valojakson pituus. Kukinnan kannalta kriittinen päivänpituus $15^{\circ} \mathrm{C}$ :een lämpötilassa on 11-16 h lajikkeesta riippuen (Heide 1977, Sonsteby \& Nes 1998). Päivänpituuden lyhentyessä myös lehtiruotien pituuskasvu heikkenee voimakkaasti ja lopulta kasvu pysähtyy (Jonkers 1965). Lisäksi päivänpituus vaikuttaa hankasilmujen erilaistumiseen: Pitkä päivä edistää rönsyntuotantoa ja lyhyessä päivässä hankasilmut erilaistuvat juurakon haaroiksi (Darrow 1966, Konsin ym. 2001, Hytönen ym. julkaisematon). Juurakon riittävä haaroittuminen on tärkeää, koska mansikan kukinnot muodostuvat juurakon ja sen haarojen kärkikasvupisteistä.

Mansikan hankasilmujen erilaistuminen on osittain kasvihormonien säätelemää. Aiemmissa tutkimuksissa on selvitetty gibberelliinin (GA), GA synteesi-inhibiittori paclobutrazolin ja sytokiniinin vaikutuksia mansikan juurakon haaroittumiseen ja rönsyntuotantoon (Thompson \& Guttridge 1959, Braun \& Kender 1985, Pritts ym. 1986 ja Nishizawa 1993). Sekä gibberelliini että sytokiniini näyttävät vaikuttavan hankasilmujen erilaistumiseen, mutta tulokset ovat osin ristiriitaisia.

Suomessa istutetaan vuosittain useita miljoonia mansikan satotaimia, eli istutusvuonna satoa tuottavia taimia. Pääosa taimista tuodaan Hollannista ja niiden mukana on Suomeen saapunut vaarallinen kasvitauti, mustalaikku. Suomalaisissa varmennetun taimituotannon taimissa mustalaikkua ei ole havaittu. Suomessa avomaalla tuotetut yksivuotiset satotaimet jäävät kuitenkin liian pieniksi pystyäkseen tuottamaan kunnon sadon istutusvuonna. Ongelmana on juurakon haaroittumisen käynnistyminen vasta syksyllä, jolloin kasvukausi on jo lähes päättynyt. Kesällä pitkä päivittäinen valojakso lisää rönsyntuotantoa ja estää juurakon haaroittumisen. Juurakon riittävä haaroittuminen on olennaista, koska kukinnot muodostuvat haarojen kärkisilmuista. Tässä tutkimuksessa selvitettiin päivänpituuden, proheksadioni-kalsiumin (ProCa) ja GA3:n vaikutusta mansikantaimen vegetatiiviseen ja generatiiviseen kasvuun kasvihuoneessa. ProCa on GA-synteesi-inhibiittori, joka estää GA-3ß-hydroksylaasin toiminnan pysäyttäen aktiivisten gibberelliinien, GA1:n ja GA4:n, muodostumisen niiden esiasteista, GA20 ja GA9 (Rademacher 2000). Tutkimuksen tavoitteena oli löytää keinoja mansikan juurakon haaroittumisen lisäämiseksi.

\section{Aineisto ja menetelmät}

ProCa:n vaikutusta 'Koronan' kasvuun ja hankasilmujen erilaistumiseen selvitettiin kahdessa kokeessa vuosina 2002-2003. Molemmissa kokeissa käytettiin noin kahdeksan viikon ikäisiä taimia, jotka oli kasvatettu pitkässä päivässä. Taimikasvatuksen aikana taimia valotettiin $18 \mathrm{~h}$ vuorokaudessa suurpainenatriumlampuilla (Osram NAV-T 400W) intensiteetillä $80 \pm 10 \mu \mathrm{mol} \mathrm{m}^{-2} \mathrm{~s}^{-1}$. Ensimmäisessä kokeessa (21.10.2002-17.1.2003) tutkittiin ProCa-konsentraation $(0,50,125,200 \mathrm{ppm})$ vaikutusta kolmessa päivänpituudessa $(10,14$ ja 18 h). Eri ProCa-pitoisuuksien tulokset kuitenkin yhdistettiin, koska $50 \mathrm{ppm}: n$ pitoisuudella saatiin aikaan täysi vaikutus ja pitoisuuksien välillä ei ollut merkittäviä eroja. Kaikkia taimia valotettiin suurpainenatriumlampuilla $10 \mathrm{~h} /$ vrk (klo 7.00-17.00) intensiteetillä $80 \pm 10$ $\mu$ molm ${ }^{-2} \mathrm{~s}^{-1}$. Päivänpidennys toteutettiin hehkulampuilla alhaisella intensiteetillä $\left(5 \pm 1 \mu \mathrm{mol} \mathrm{m} \mathrm{m}^{-2} \mathrm{~s}^{-1}\right)$ heti ensimmäisen valojakson jälkeen. Lämpötila pidettiin koko kokeen ajan $18^{\circ} \mathrm{C}$ :ssa. ProCa-käsittelyt tehtiin ruiskuttamalla taimien lehdet märiksi sumupullolla ja kontrollitaimet ruiskutettiin vastaavasti puhtaalla vedellä. Ensimmäisessä kokeessa taimien annettiin kasvaa 12 viikkoa ProCa-käsittelyiden jälkeen. 
Toisessa kokeessa oli yksi ProCa-käsittely (50 ppm) sekä kontrolli. Taimet pidettiin koko kokeen ajan pitkässä päivässä valottamalla niitä suurpainenatriumlampuilla (Osram NAV-T 400W) $18 \mathrm{~h} /$ vrk intensiteetillä $80 \pm 10 \mu \mathrm{mol} \mathrm{m} \mathrm{m}^{-2}$. Kasvihuoneosaston lämpötila pidettiin $18^{\circ} \mathrm{C}$ :ssa. Osalle ProCa-käsitellyistä taimista tehtiin GA3-käsittely pipetoimalla $5 \mu 1 \mathrm{GA} 3$-liuosta $(5 \mu \mathrm{g}$ GA3 / $1 \mu \mathrm{l} \mathrm{EtOH})$ nuorimman lehden kärkeen yhden ja kahden viikon kuluttua ProCa-käsittelystä. Kontrollitaimet käsiteltiin vastaavasti etanolilla. Taimien annettiin kasvaa 10 viikkoa ennen mittauksia.

ProCa:n vaikutusta vegetatiiviseen kasvuun seurattiin ensimmäisessä kokeessa mittaamalla nuorimman rönsyn kahden ensimmäisen nivelvälin ja nuorimman lehtiruodin pituuskasvua kolmesti viikossa päivänpituuskäsittelyiden alusta lähtien. Kokeen päättyessä mitattiin pisimmän rönsyn pituus ja laskettiin sen nivelien lukumäärä. Molemmissa kokeissa laskettiin juurakon haarojen ja rönsyjen lukumäärät kokeen päättyessä ja selvitettiin stereomikroskoopin avulla olivatko pääjuurakon ja sen haarojen kärkimeristeemit vegetatiivisia vai generatiivisia.

\section{Tulokset ja tulosten tarkastelu}

Sekä ProCa, että päivänpituus vaikuttivat voimakkaasti taimien vegetatiiviseen kasvuun. Päivänpituuden lyhentäminen 18:sta kymmeneen tuntiin vähensi kokeen alussa merkityn nuorimman lehtiruodin pituuskasvua kontrollitaimissa noin 50\% (Kuva 1). Kaikissa ProCa:lla käsitellyissä taimissa nuorin lehtiruoti jäi kuitenkin huomattavasti lyhyemmäksi kuin kontrollitaimissa ja ProCa:n vaikutus oli havaittavissa jo kahden päivän kuluttua käsittelystä. Päivänpituuden lyheneminen vähensi hieman myös ProCa-käsiteltyjen taimien lehtiruotien pituuskasvua. Aiemmissa GA-synteesi-inhibiittori paclobutrazolilla tehdyissä kokeissa on saatu hyvin samansuuntaisia tuloksia (Wiseman \& Turnbull 1999a). Näiden kokeiden perusteella GA:1lä näyttää olevan tärkeä rooli mansikan lehtiruotien pituuskasvun säätelyssä. GA ei kuitenkaan ole ainoa tekijä, koska päivänpituuden lyhentäminen hidasti myös ProCakäsiteltyjen taimien lehtiruotien kasvua. Wiseman \& Turnbull (1999b) analysoivat lyhyessä ja pitkässä päivässä kasvaneiden lehtiruotien GA-pitoisuuksia, mutta eivät löytäneet yhteyttä mansikan lehtiruodin pituuskasvun muutosten ja GA-pitoisuuksien väliltä.

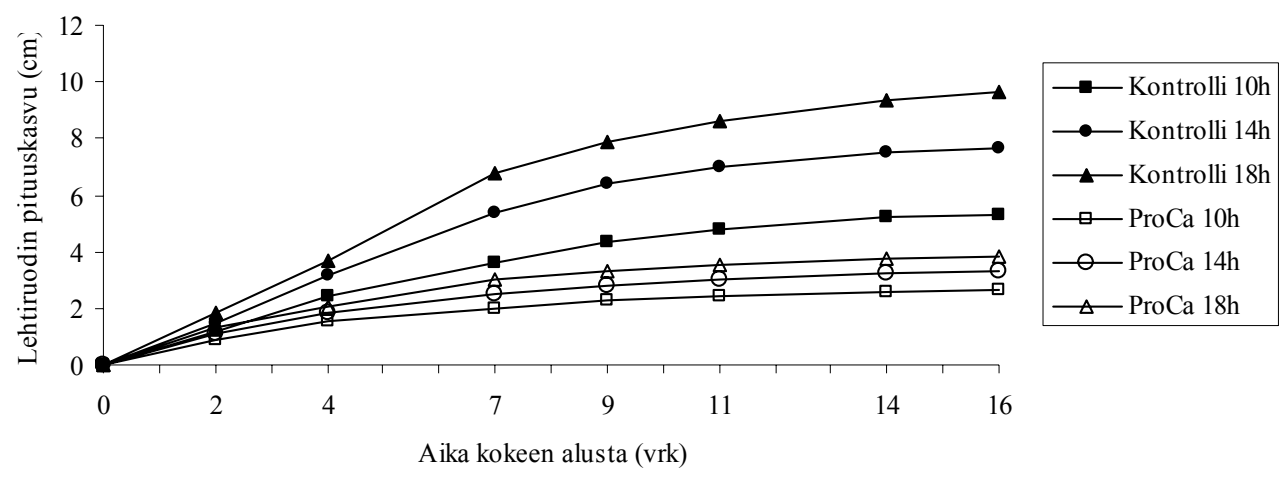

KUVA 1. Proheksadioni-kalsiumin ja päivänpituuden vaikutus nuorimman lehtiruodin pituuskasvuun käsittelyiden alusta lähtien.

Päivänpituus ei vaikuttanut nuorimman rönsyn kahden ensimmäisen nivelvälin pituuskasvuun (Kuva 2), mutta rönsyjen kasvu pysähtyi 10 ja 14 tunnin päivänpituuksissa ensimmäisen tai viimeistään toisen rönsytaimen jälkeen. Pisimmässä rönsyssä oli 10 ja 14 tunnin päivänpituudessa keskimäärin kolme ja pitkässä päivässä kahdeksan niveltä kokeen päättyessä. ProCa vähensi rönsyjen pituuskasvua 50-60 $\%$ ja rönsyjen kasvu pysähtyi lähes kaikissa taimissa ensimmäiseen rönsytaimeen. Myös Paclobutrazolin on havaittu hidastavan rönsyjen pituuskasvua voimakkaasti ja vähentävän rönsyjen sekä rönsytaimien kuivapainoa (Nishizawa 1993). GA näyttää siis vaikuttavan voimakkaasti rönsyn pituuskasvuun ja uusien rönsytaimien tuotantoon. Rönsyjen lukumäärissä ei ollut eroja käsittelyjen välillä, koska taimet eivät tehneet uusia rönsyjä kokeen aikana. Tämä johtui ilmeisesti päivänpidennysvalotuksen alhaisesta intensiteetistä. 


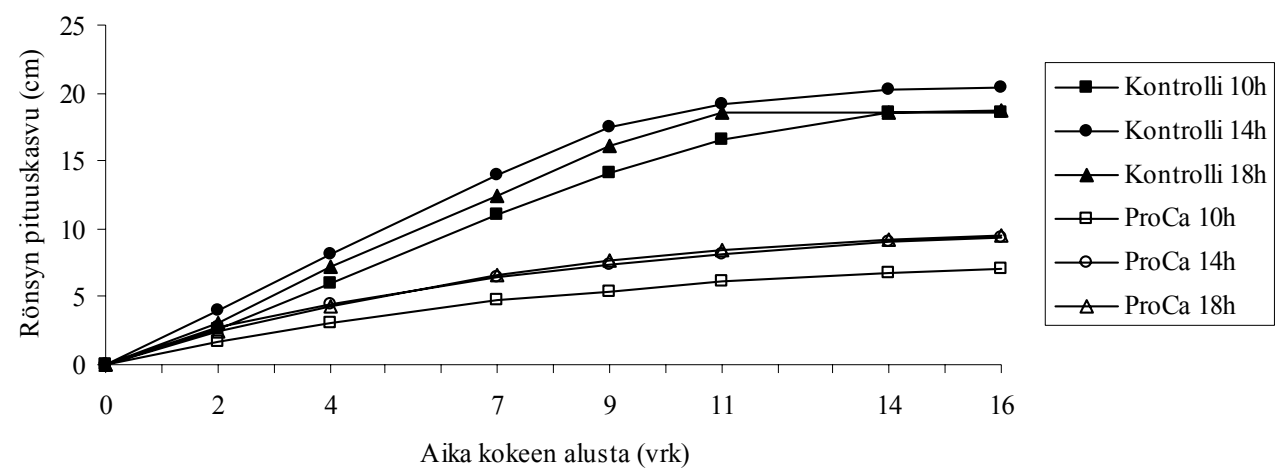

KUVA 2. Proheksadioni-kalsiumin ja päivänpituuden vaikutus nuorimman rönsyn pituuskasvuun käsittelyiden alusta lähtien.

Kymmenen ja 14 tunnin päivänpituuksissa kaikkiin taimiin muodostui juurakon haaroja riippumatta ProCa-käsittelystä. Tulokset osoittavat, että kriittinen päivänpituus juurakon haaroittumiselle ja rönsyjonon kasvulle on 'Koronalla' 14 ja 18 tunnin välissä. ProCa vaikutti juurakon haaroittumiseen ainoastaan 18 h:n päivänpituudessa, jossa se lisäsi haaroittumista. Toisessa kokeessa ProCa lisäsi juurakon haaroittumista ja vähensi rönsyntuotantoa huomattavasti (Kuva 3). GA3-käsittely kumosi ProCa:n vaikutuksen haaroittumiseen ja lisäsi rönsyntuotantoa suhteessa kontrolliin. Myös aikaisemmissa kokeissa on saatu samansuuntaisia tuloksia: Paclobutrazolin on havaittu lisäävän haaroittumista ja vähentävän rönsyjen lukumäärää (Nishizawa 1993), ja GA-käsittelyn tiedetään lisäävän rönsyntuotantoa (Thompson \& Guttridge 1959). GA:1lä näyttää siis olevan merkittävä rooli myös mansikan hankasilmujen erilaistumisen säätelyssä. Kun aktiivisten GA:en määrä mansikalla laskee, rönsyntuotanto pysähtyy ja juurakon haarojen muodostus käynnistyy. Näissä kokeissa ProCa:n ei havaittu vaikuttavan kukintainduktioon.

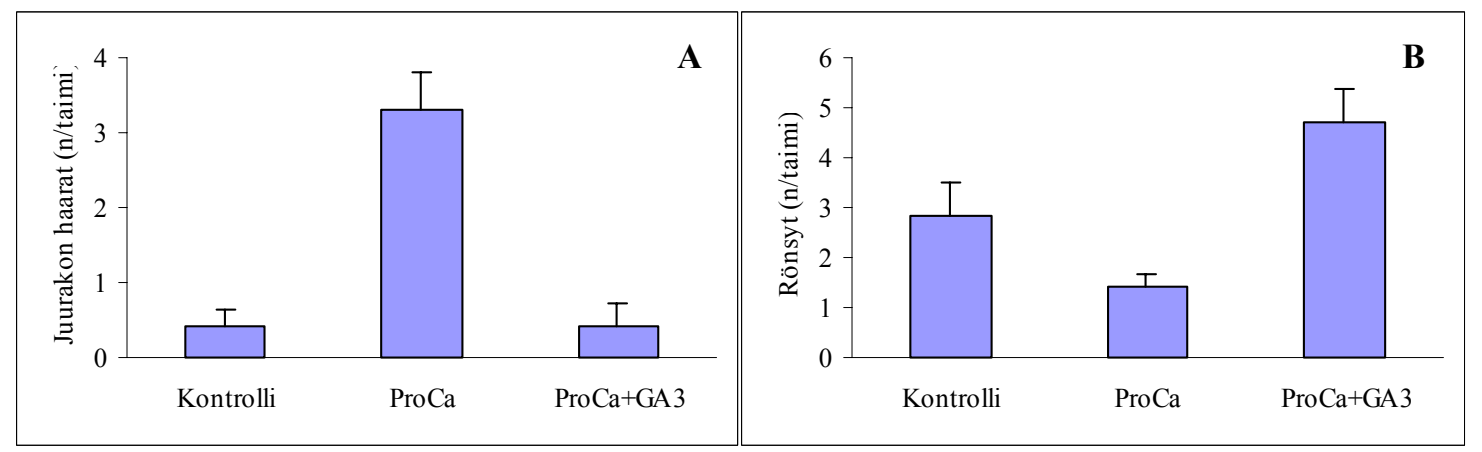

KUVA 3. Proheksadioni-kalsiumin (50 ppm) ja GA3:n vaikutus A) juurakon haaroittumiseen ja B) rönsyntuotantoon 18 tunnin päivänpituudessa. Janat pylväiden päissä kuvaavat keskiarvon keskivirhettä.

\section{Johtopäätökset}

Tekemämme kokeet osoittavat, että GA:llä on merkittävä rooli mansikan hankasilmujen erilaistumisessa juurakon haaroiksi ja rönsyiksi. GA-synteesin hillitseminen ProCa:lla lisäsi juurakon haaroittumista ja vähensi rönsyntuotantoa pitkänpäivän olosuhteissa ja ProCa:n vaikutus kumoutui täysin GA3käsittelyllä. Suomen päivänpituusolot ohjaavat mansikan hankasilmujen erilaistumista sadontuotannon kannalta väärään suuntaan: pitkästä päivästä johtuen mansikan rönsyntuotanto on voimakasta vielä elokuussa ja juurakon haaroittuminen alkaa vasta elokuun lopussa. ProCa-käsittelyillä voidaan todennäköisesti parantaa merkittävästi suomalaisen satotaimen satopotentiaalia. Käytännössä juurakon haaroittuminen voidaan käynnistää ja rönsyntuotanto pysäyttää kesällä tehtävällä ProCa-käsittelyllä, jolloin taimiin muodostuu enemmän paikkoja kukinnoille. Lisäksi yhteyttämistuotteet voidaan paremmin 
suunnata satopotentiaalin muodostamiseen, kun turha rönsyntuotanto estyy. ProCa vaikuttaa voimakkaasti myös lehtiruotien pituuskasvuun, jolloin satotaimien vaatima tila on pienempi ja taimia on mahdollista kasvattaa tiheämmässä. ProCa-käsittelyitä voidaan mahdollisesti hyödyntää myös satokauden jälkeisen rönsyntuotannon pysäyttämisessä avomaan mansikkakasvustoilla.

\section{Kirjallisuus}

Braun, J. W. \& Kender, W. J. 1985. Correlative bud inhibition and growth habit of the strawberry as influenced by application of gibberellic acid, cytokinin, and chilling during short daylength. Journal of the American Society for Horticultural Science 110: 28-34.

Darrow, G. M. 1966. The Strawberry. History, breeding and physiology. Holt, Rinehart and Winston, New York.

Guttridge, C. 1985. Fragaria x ananassa. In: Halevy, A. (ed.). CRC Handbook of flowering. Vol. III. Boca Raton: CRC press. p. 16-33.

Heide, O. M. 1977. Photoperiod and temperature interactions in growth and flowering of strawberry. Physiologia Plantarum 40: 21-26.

Jonkers, H. 1965. On the flower formation, the dormancy and the early forcing of strawberries. Mededelingen van de Landbouwhogeschool. Thesis, Wageningen.

Konsin, M., Voipio, I. \& Palonen, P. 2001. Influence of photoperiod and duration of short-day treatment on vegetative growth and flowering of strawberry (Fragaria x ananassa Duch.). Journal of Horticultural Science and Biotechnology 76: 77-82.

Nishizawa, T. 1993. The effect of paclobutrazol on growth and yield during first year greenhouse strawberry production. Scientia Horticulturae 54: 267-274.

Pritts, M. P., Posner, G. S. \& Worden, K. A. 1986. Effects of 6-BA application on growth and development in 'Tristar', a strong day-neutral strawberry. HortScience 21: 1421-1423.

Rademacher, W. 2000. Growth retardants: Effects on gibberellin biosynthesis and other metabolic pathways. Annual Review in Plant Physiology and Plant Molecular Biology 51: 501-531.

Sonsteby, A. \& Nes, A. 1998. Short days and temperature effects on growth and flowering in strawberry (Fragaria $\mathrm{x}$ ananassa Duch.). Journal of Horticultural Science and Biotechnology 73: 730-736.

Thompson, P. A. \& Guttridge, C. G. 1959. Effect of gibberellic acid on the initiation of flowers and runners in the strawberry. Nature 184: 72-73.

Wiseman, N. J. \& Turnbull, C. G. N. 1999a. Effects of photoperiod and paclobutrazol on growth dynamics of petioles in strawberry. Australian Journal of Plant Physiology 26: 353-358.

Wiseman, N. J. \& Turnbull, C. G. N. 1999b. Endogenous gibberellin content does not correlate with photoperiod induced growth changes in strawberry petioles. Australian Journal of Plant Physiology 26: 359-366. 